\title{
The Influence of Air Contact on the Quality of Extended Boar Semen
}

\author{
Caroline de Veronez Ribeiro', Júlia Linck Moroni', Mariana Boscato Menegat', \\ Ana Paula Gonçalves Mellagi', Mari Lourdes Bernardi'2, Ivo Wentz' \& Fernando Pandolfo Bortolozzo'
}

\begin{abstract}
Background: The extensive use of artificial insemination in the swine industry emphasizes the need for distribution of good quality semen doses by the artificial insemination centers. A factor that could modify seminal quality is the contact of extended semen with environmental air. However, only few studies have investigated the effects of air presence on semen parameters. Thus, the aim of the present study was to evaluate the influence of different amounts of air on porcine semen quality during the storage period.

Materials, Methods \& Results: Four ejaculates from five sexually mature boars were used. Each ejaculate $(\mathrm{n}=20)$ was isothermically diluted $\left(30 \times 10^{6} / \mathrm{mL}\right)$ in a BTS-extender and assigned to three groups differing on the amount of air entrapped within the polystyrene tubes $(100 \mathrm{~mL})$. In group AIR-0 the tubes were completely filled with extended semen $(0 \%$ air); in group AIR-25, 75\% of the tube volume was filled with extended semen and $25 \%$ with air; in group AIR-50, 50\% of the tube volume was filled with extended semen. The semen doses were stored at $17.3 \pm 0.5^{\circ} \mathrm{C}$ for $120 \mathrm{~h}$. The motility parameters were assessed at 24,72 and $120 \mathrm{~h}$ of storage using a CASA system. The evaluation of acrosomal integrity was performed by examining formalin-fixed samples under phase-contrast microscopy $(1000 \mathrm{x})$ at 72 and $120 \mathrm{~h}$ of storage. The $\mathrm{pH}$ was measured at $24,48,72$, and $120 \mathrm{~h}$ of storage with a digital $\mathrm{pH}$-meter. At $120 \mathrm{~h}$, samples were incubated in waterbath at $38^{\circ} \mathrm{C}$ for the thermoresistance test and sperm motility was assessed after 30 and 120 min of incubation. For each time analysis, a different sealed tube was used in order to maintain a constant amount of air within the tubes during storage. Data were analyzed as repeated measures using the GLIMMIX procedure of SAS ${ }^{\circledR}$ Software. Boar and week of collection were included as random effect in the model. Groups were compared using the Tukey-Kramer test at a significance level of $5 \%$. The $\mathrm{pH}$ was significantly influenced by the amount of air entrapped within the tubes $(P<0.01)$. Throughout the experiment, the $\mathrm{pH}$ of semen doses was higher as the amount of air increased within the tubes. The mean $\mathrm{pH}$ for groups AIR-50, AIR-25 and AIR-0 was 7.51 $\pm 0.06,7.25 \pm 0.06$ and $7.07 \pm 0.06$, respectively. Overall motility was similar among the groups for up to $24 \mathrm{~h}$ of storage. At $72 \mathrm{~h}$ and $120 \mathrm{~h}$ of storage, total, progressive and rapid motility were higher $(P<$ 0.05) in AIR-0 compared to AIR-50. The kinematic parameters DAP and VAP decreased as the volume of air within the tubes increased $(P<0.05)$. Group AIR-0 exhibited higher values $(P<0.05)$ for DSL, DCL, VSL, VCL, BCF, and WOB compared to AIR-25 and AIR-50. Furthermore, after the thermoresistance test performed at $120 \mathrm{~h}$ of storage, total motility, progressive motility and rapid motility were negatively affected $(P<0.05)$ by the increasing amounts of air within the tubes. There was no effect of air amount within the semen doses on acrosome integrity $(P>0.05)$.

Discussion: The presence of air within tubes affects the quality of extended semen during storage, resulting in increase of $\mathrm{pH}$ and subsequent decrease in motility preservation. This $\mathrm{pH}$-rise could be explained by the loss of $\mathrm{CO}_{2}$ from the diluted semen to the air compartment within the tube. At the same time, it is possible to infer that this event influences the intracellular $\mathrm{pH}$ of the spermatozoa, increasing sperm metabolism and, consequently, impairing sperm motility. Therefore, we conclude that avoiding air presence within storage containers is recommended in order to ensure the quality of boar semen doses.
\end{abstract}

Keywords: semen dose, air, pH, sperm motility. 


\section{INTRODUCTION}

The efficiency in swine reproduction has dramatically increased during the last decade. Currently, approximately 2000 artificial insemination doses can be manufactured per hour [11]. At the same time, as production intensity is increased, a strict quality level for semen doses has been required. Therefore, artificial insemination centers aim at providing a product that has high biosecurity, high genetic value and high fertilization potential [11].

Several factors may influence the quality of cooled semen doses, including storage temperature [6], storage length [16], dilution rate [12], and extender composition [8]. Another factor that could modify seminal quality is the contact of extended semen with environmental air. It has been suggested that this element has a detrimental effect on sperm motility and other sperm kinematic parameters [15]. Consequently, it has been recommended that its presence should be minimized in order to ensure the longevity of semen doses $[1,11,15]$. Nevertheless, this guidance is not routinely followed and the amount of air within spermcontaining tubes is not standardized. Many artificial insemination centers use a standard package to store all semen doses, without considering the volume of extended semen infused into each one. Therefore, when the container capacity is greater than the volume of extended semen, an undesired amount of air remains entrapped in semen doses.

The aim of the present study was to evaluate the influence of different amounts of air on porcine semen quality during the storage period.

\section{MATERIALS AND METHODS}

\section{Semen collection and processing}

Five healthy mature boars ( 1 to 3 years of age) were used in this study. From each boar, four ejaculates were collected and subsequently processed $(n=20)$. Collections were performed using the gloved-hand technique [5] and placed into pre-warmed collection cups $\left(38^{\circ} \mathrm{C}\right)$. Prior to dilution, samples from each ejaculate were evaluated for sperm motility, morphology and concentration. Only ejaculates that met or exceeded the minimum of $80 \%$ morphologically normal cells and $70 \%$ total sperm motility were selected for the study.

The semen was diluted in a BTS-extender ${ }^{1}$ (Beltsville Thawing Solution) to a final concentration of approximately 30 million sperms per milliliter $(30 \mathrm{x}$ $10 \% \mathrm{~mL}$ ). After dilution, semen doses were assigned in a split-sample design to three groups differing on the amount of air entrapped within the storage containers (closed polystyrene tubes of $100 \mathrm{~mL}$ ). In group AIR-0 the tubes were completely filled with extended semen ( $0 \%$ air); in group AIR-25, $75 \%$ of the tube volume was filled with extended semen and $25 \%$ with air; in group AIR-50, $50 \%$ of the tube volume was filled with extended semen and $50 \%$ with air. The volume of extended semen stored in each tube was carefully measured using a precision scale (Shimadzu BL3200H) ${ }^{2}$ to obtain $100 \mathrm{~mL}, 75 \mathrm{~mL}$ and $50 \mathrm{~mL}$ in groups AIR-0, AIR-25 and AIR-50, respectively. All semen doses were stored in the same temperature-controlled cabinet $\left(17.3 \pm 0.5^{\circ} \mathrm{C}\right)$ for $120 \mathrm{~h}$.

\section{Semen examination}

Sperm motility was assessed using a CASA system $^{1}$ (Computer-Assisted Sperm Analysis) at 24, 72 and $120 \mathrm{~h}$ of storage. For analysis, an aliquot of $1 \mathrm{~mL}$ of the semen dose was incubated at $37^{\circ} \mathrm{C}$ in a thermoblock for $10 \mathrm{~min}$. By capillary flow, samples of $3 \mu \mathrm{L}$ were placed in a $20 \mu \mathrm{m}$-depth counting chamber ${ }^{3}$ and then analyzed under phase contrast microscopy (Axio Scope.A1) ${ }^{4}$ [200x total magnification]. The motility parameters determined by the software were total motility, progressive motility, rapid motility, slow motility, circular motility, and local motility. The following kinematic parameters were also provided by the CASA system: DCL - curvilinear distance $(\mu \mathrm{m})$; DSL - straight-line distance $(\mu \mathrm{m})$; DAP - average path distance $(\mu \mathrm{m})$; VCL - curvilinear velocity $(\mu \mathrm{m} / \mathrm{s})$; VSL - straight-line velocity $(\mu \mathrm{m} / \mathrm{s})$; VAP - average path velocity $(\mu \mathrm{m} / \mathrm{s}) ; \mathrm{ALH}$ - amplitude of lateral head displacement $(\mu \mathrm{m})$; BCF - beat-cross frequency $(\mathrm{Hz})$; LIN - linearity (VSL/VCL); STR - straightness (VSL/ VAP); and WOB - wobble (VAP/VCL).

The sperm morphology was assessed in formalin-fixed samples of raw semen under phase-contrast microscopy (1000x total magnification). Two hundred spermatozoa per sample were analyzed. Morphological classification included the percentages of normal spermatozoa, abnormal head, acrosome defect, abnormal midpiece, attached proximal cytoplasmic droplets, attached distal cytoplasmic droplets, folded tail, and coiled tail. Following a similar protocol for sample preparation and analysis, the assessment of acrosome integrity was performed in formalin-fixed samples of 
extended semen after $72 \mathrm{~h}$ and $120 \mathrm{~h}$ of storage. The sperm cells were classified as having normal or altered acrosomes. The acrosomal status was expressed as the percentage of sperm cells with abnormal acrosomal morphology.

A thermoresistance test (TRT) was performed at $120 \mathrm{~h}$ of storage. An aliquot of $10 \mathrm{~mL}$ of each semen dose was incubated in water bath $\left(\text { Braun Biotech }{ }^{\circledR}\right)^{5}$ at $38^{\circ} \mathrm{C}$ for up to $120 \mathrm{~min}$. Sperm motility was assessed at 30 and 120 min of incubation, using the CASA system as described above.

The $\mathrm{pH}$ of the semen doses was measured at $24,48,72$ and $120 \mathrm{~h}$ of storage with a previously calibrated digital $\mathrm{pH}$-meter $\left(\mathrm{QUIMIS}^{\circledR} \mathrm{Q} 400 \mathrm{AS} \text {. }\right)^{6}$. The $\mathrm{pH}$ electrode was washed with distilled water and wiped between analyses.

\section{Statistical analysis}

Data were analyzed as repeated measures using the GLIMMIX procedure of SAS ${ }^{\circledR}$ Software. Groups, storage time and its interaction were included in the model as fixed effects, whereas boar and week of collection were included as random effect. For TTR data, the incubation time (30 and $120 \mathrm{~min}$ ) was included in the model as repeated measure. Total, progressive, rapid, slow, circular, and local motility were analyzed considering a binomial distribution. Values are expressed as LSmean \pm standard error of the mean. Groups and storage time were compared using the Tukey-Kramer test at a significance level of 5\%.

\section{RESULTS}

Overall, the percentages of total motility, progressive motility, and morphologically normal spermatozoa in raw semen were $86.4 \pm 0.5 \%, 80.4 \pm$ $0.3 \%$, and $95.1 \pm 0.6 \%$, respectively.

Figure 1 illustrates the effect of air on the $\mathrm{pH}$. Significant differences were observed among the groups $(P<0.01)$. The $\mathrm{pH}$ of semen doses was higher as the amount of air increased within the tubes (means of 7.07 $\pm 0.04,7.25 \pm 0.04$ and $7.52 \pm 0.04$ for AIR-0, AIR-25 and AIR-50, respectively).

The results for the motility parameters are summarized in Figure 2. An interaction between the amount of air within the tubes and storage time $(P<$ $0.05)$ was observed for total, progressive, rapid, slow, and local motility. Overall, motility was similar among the groups for up to $24 \mathrm{~h}$ of storage, while the effect of air on motility was evidenced after $72 \mathrm{~h}$ of storage.
Total (Figure 2A) and progressive (Figure 2B) motility were lower $(P<0.05)$ in AIR-50 compared to AIR0 and AIR-25, at $72 \mathrm{~h}$ and $120 \mathrm{~h}$ of storage; but no significant difference was observed between the latter two groups $(P>0.05)$. The percentage of rapid spermatozoa (Figure $2 \mathrm{C}$ ) was inferior $(P<0.05)$ in AIR-50 compared to AIR-0, at $72 \mathrm{~h}$ and $120 \mathrm{~h}$ of storage. Slow motility was lower $(P<0.05)$ in AIR-50 compared to AIR-0, but only at $120 \mathrm{~h}$ of storage (Figure $2 \mathrm{D}$ ). The percentage of local motility (Figure 2E) was increased $(P<0.05)$ in AIR-50 compared to AIR-0, at $72 \mathrm{~h}$ of storage. No significant difference $(P>0.05)$ in rapid, slow and local sperm motility was noted between AIR25 and the other groups.

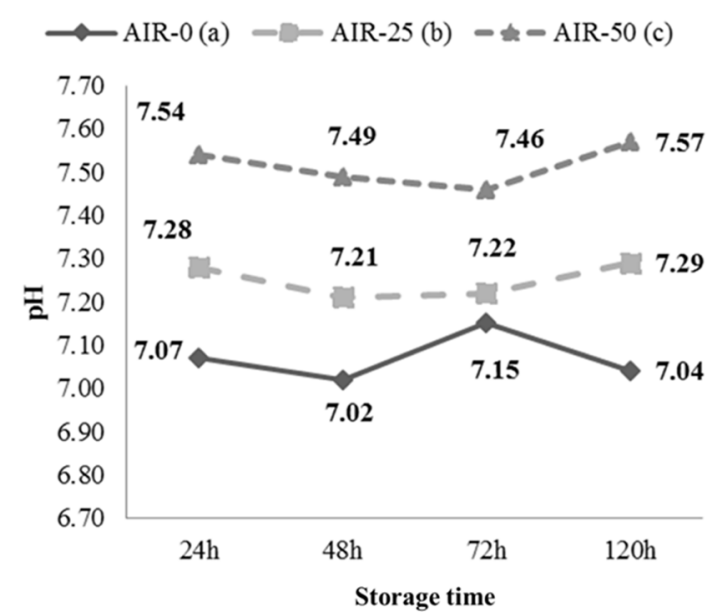

Figure 1. The $\mathrm{pH}$ of boar semen doses containing different amounts of air within the tubes during a 5-day storage period. Groups with a different letter were statistically different $(P<0.01)$. AIR-0 ( $0 \%$ air), AIR-25 (25\% air) and AIR-50 (50\% air).

The circular motility was not affected by the interaction between the amount of air within the tubes and storage time $(P>0.05)$. The amount of air influenced the circular motility with AIR-0 group having superior circular motility $(P<0.05)$ compared to AIR-25 $(0.51 \pm 0.12 \%$ and $0.17 \pm 0.06 \%$, respectively). Group AIR-50 presented intermediate values and did not differ from the others $(0.29 \pm 0.07 \%)$.

There was no effect of the interaction between the amount of air within the tubes and storage time $(P>$ $0.05)$ on some kinematic parameters, which are shown in Table 1, regardless of the storage time. DAP and VAP decreased $(P<0.05)$ as the volume of air within the tubes increased. Group AIR-0 exhibited higher values $(P<0.05)$ for DCL, VCL, DSL, VSL, BCF, and WOB compared to AIR-25 and AIR-50; nevertheless, no difference was observed between the latter two groups 
$(P>0.05)$ for these variables. The parameters STR and LIN were not influenced by the amount of air entrapped within tubes $(P>0.05)$.

A significant interaction between group and storage time $(P<0.05)$ was verified for ALH. There were no differences among the groups at 24 and $72 \mathrm{~h}$, but at $120 \mathrm{~h}$ of storage ALH decreased $(P<0.05)$ as the amount of air increased $(0.97 \pm 0.05 \mu \mathrm{m} ; 0.80 \pm$ $0.05 \mu \mathrm{m}$; and $0.63 \pm 0.05 \mu \mathrm{m}$ for AIR-0, AIR-25 and AIR-50, respectively).

No difference $(P>0.05)$ in the percentages of abnormal acrosome was observed among the groups (AIR-0: $3.62 \pm 0.25 \%$; AIR-25: $3.79 \pm 0.25 \%$; AIR50: $4.12 \pm 0.27 \%)$. However, the percentage of sperm cells with abnormal acrosomal morphology increased at $120 \mathrm{~h}$ of storage compared to $72 \mathrm{~h}(4.49 \pm 0.24 \%$ vs $3.28 \pm 0.19 \%$, respectively; $P<0.0001)$. After the thermoresistance test performed at $120 \mathrm{~h}$ of storage, total motility, progressive motility and rapid motility were increased as the amount of air within tubes decreased $(P<0.05$; Table 2$)$. Regarding slow motility, group AIR-50 showed an inferior value compared to AIR-0 and AIR-25 $(P<0.05)$, but no statistical difference was noted between AIR-0 and AIR-25. Furthermore, the amount of air had no influence on circular and local motility $(P>0.05)$. A clear decline was observed in all motility parameters when incubation time was increased from $30 \mathrm{~min}$ to $120 \mathrm{~min}(P<0.05$; Table 2$)$.
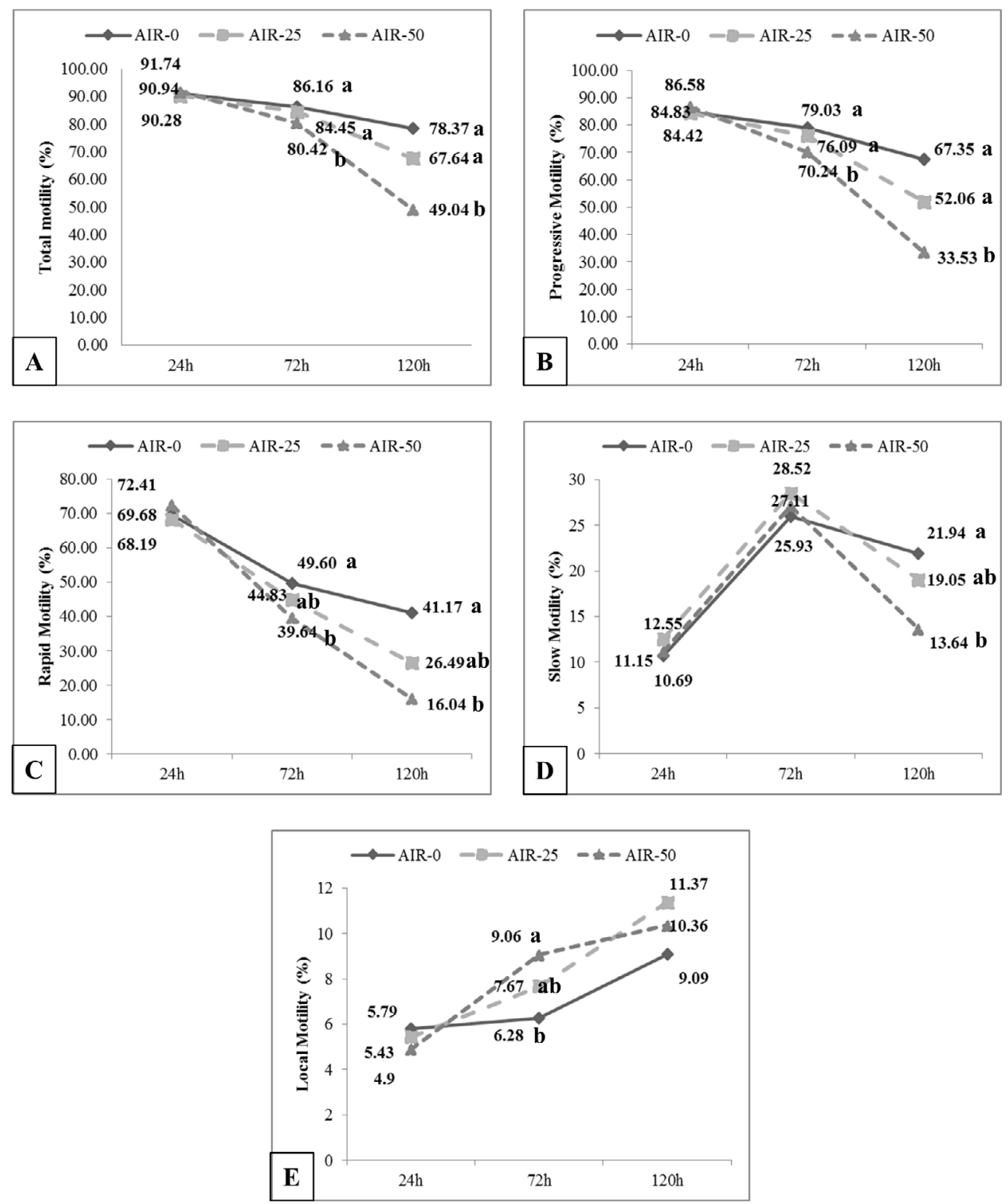

Figure 2. Effect of the interaction between the amount of air entrapped within the tubes and storage time on motility parameters of boar semen doses. AIR-0 (0\% air), AIR-25 (25\% air) and AIR-50 (50\% air). Values with a different letter were statistically different $(P<0.05)$ within each time point of evaluation. 
Table 1. Kinematic parameters of boar semen doses containing different amounts of air entrapped within the tubes, regardless of the storage time.

\begin{tabular}{cccc}
\hline Kinematic Parameter & AIR-0 & AIR-25 & AIR-50 \\
\hline DAP, $\mu \mathrm{m}$ & $16.93 \pm 0.56^{\mathrm{a}}$ & $14.69 \pm 0.56^{\mathrm{b}}$ & $13.63 \pm 0.56^{\mathrm{c}}$ \\
VAP, $\mu \mathrm{m} / \mathrm{s}$ & $41.19 \pm 1.49^{\mathrm{a}}$ & $35.71 \pm 1.49^{\mathrm{b}}$ & $32.84 \pm 1.49^{\mathrm{c}}$ \\
DCL, $\mu \mathrm{m}$ & $40.16 \pm 1.36^{\mathrm{a}}$ & $35.94 \pm 1.36^{\mathrm{b}}$ & $33.98 \pm 1.36^{\mathrm{b}}$ \\
VCL, $\mu \mathrm{m} / \mathrm{s}$ & $97.09 \pm 3.60^{\mathrm{a}}$ & $86.65 \pm 3.60^{\mathrm{b}}$ & $81.10 \pm 3.60^{\mathrm{b}}$ \\
DSL, $\mu \mathrm{m}$ & $11.64 \pm 0.38^{\mathrm{a}}$ & $10.19 \pm 0.38^{\mathrm{b}}$ & $9.56 \pm 0.38^{\mathrm{b}}$ \\
VSL, $\mu \mathrm{m} / \mathrm{s}$ & $28.69 \pm 0.99^{\mathrm{a}}$ & $25.05 \pm 0.99^{\mathrm{b}}$ & $23.31 \pm 0.99^{\mathrm{b}}$ \\
BCF, Hz & $16.31 \pm 0.47^{\mathrm{a}}$ & $14.27 \pm 0.47^{\mathrm{b}}$ & $13.43 \pm 0.47^{\mathrm{b}}$ \\
WOB, $\%$ & $42.34 \pm 0.44^{\mathrm{a}}$ & $41.18 \pm 0.44^{\mathrm{b}}$ & $41.08 \pm 0.44^{\mathrm{b}}$ \\
STR, $\%$ & $65.57 \pm 0.94$ & $64.38 \pm 0.94$ & $64.45 \pm 0.94$ \\
LIN, $\%$ & $29.85 \pm 0.64$ & $28.83 \pm 0.64$ & $29.19 \pm 0.64$ \\
\hline
\end{tabular}

Values expressed as LSMean \pm Standard Error of Mean. Values with different superscripts within a row differ significantly $(P<0.05)$. AIR- $0=0 \%$ air; AIR $-25=25 \%$ air; AIR-50 $=50 \%$ air. $\mathrm{DAP}=$ average path distance; $\mathrm{VAP}=$ average path velocity; $\mathrm{DCL}=$ curvilinear distance; $\mathrm{VCL}=$ curvilinear velocity; $\mathrm{DSL}=$ straight-line distance; $\mathrm{VSL}=$ straight-line velocity; $\mathrm{BCF}=$ beat-cross frequency; $\mathrm{WOB}=$ wobble $(\mathrm{VAP} / \mathrm{VCL}) ; \mathrm{STR}=$ straightness $(\mathrm{VSL} / \mathrm{VAP}) ; \mathrm{LIN}=$ linearity $(\mathrm{VSL} / \mathrm{VCL})$.

Table 2. Motility parameters of extended boar semen after the thermoresistance test at $120 \mathrm{~h}$ of storage according to the amount of air within the tubes or to the incubation time.

\begin{tabular}{ccccccc}
\hline \multirow{2}{*}{ Motility, $\%$} & \multicolumn{3}{c}{ Groups } & & \multicolumn{2}{c}{ Incubation Time } \\
\cline { 2 - 3 } \cline { 6 - 7 } & AIR-0 & AIR-25 & AIR-50 & & $30 \mathrm{~min}$ & $120 \mathrm{~min}$ \\
\hline Total & $41.78 \pm 5.33^{\mathrm{a}}$ & $31.72 \pm 4.75^{\mathrm{b}}$ & $23.18 \pm 3.91^{\mathrm{c}}$ & & $52.87 \pm 5.25^{\mathrm{a}}$ & $16.16 \pm 2.86^{\mathrm{b}}$ \\
Progressive & $28.30 \pm 4.78^{\mathrm{a}}$ & $18.66 \pm 3.58^{\mathrm{b}}$ & $12.80 \pm 2.63^{\mathrm{c}}$ & & $36.94 \pm 5.29^{\mathrm{a}}$ & $8.74 \pm 1.82^{\mathrm{b}}$ \\
Rapid & $12.49 \pm 2.23^{\mathrm{a}}$ & $7.63 \pm 1.45^{\mathrm{b}}$ & $4.97 \pm 0.97^{\mathrm{c}}$ & & $16.35 \pm 2.54^{\mathrm{a}}$ & $3.57 \pm 0.72^{\mathrm{b}}$ \\
Slow & $11.51 \pm 1.66^{\mathrm{a}}$ & $9.00 \pm 1.34^{\mathrm{a}}$ & $6.76 \pm 1.04^{\mathrm{b}}$ & & $16.91 \pm 2.00^{\mathrm{a}}$ & $4.48 \pm 0.70^{\mathrm{b}}$ \\
Circular & $0.03 \pm 0.02$ & $0.04 \pm 0.02$ & $0.02 \pm 0.01$ & & $0.04 \pm 0.02^{\mathrm{a}}$ & $0.02 \pm 0.01^{\mathrm{b}}$ \\
Local & $8.36 \pm 0.53$ & $9.04 \pm 0.57$ & $8.15 \pm 0.53$ & & $12.19 \pm 0.70^{\mathrm{a}}$ & $5.87 \pm 0.47^{\mathrm{b}}$ \\
\hline
\end{tabular}

Values expressed as LSMean \pm Standard Error of Mean. AIR- $0=0 \%$ air; AIR-25 $=25 \%$ air; AIR- $50=50 \%$ air. Values with different superscripts within a row indicate significant difference among groups or between incubation times $(P<0.05)$.

\section{DISCUSSION}

Proper handling of semen during processing is critical for optimal quality, especially when semen doses are stored for several days before insemination [11]. The investigation about the influence of environmental air on the quality of boar semen doses is therefore relevant from a practical point of view, as its presence within semen doses is not routinely prevented in artificial insemination centers. Furthermore, only few studies in literature dealt thoroughly with this issue and the consequences involved with the presence of air within semen doses had not been completely elucidated.
Our study demonstrated that the presence of different amounts of air within sperm-containing tubes resulted in different values of $\mathrm{pH}$. A pH-rise related to the increase in the volume of air could be explained by the existence of a bicarbonate buffering system in the extender, which leads to a loss of $\mathrm{CO}_{2}$ from the diluted semen to the air compartment within the tube and, consequently, removes protons from the extender [15]. It has been demonstrated that adding $\mathrm{CO}_{2}$ in the air compartment of semen doses resulted in a minimal $\mathrm{pH}$-change, indicating that this component plays an essential role in maintaining the ionic characteristics of diluted semen [15]. 
The intracellular $\mathrm{pH}$ of the sperm may be driven by numerous extracellular stimuli. Consequently, the storage medium is capable of exerting tremendous influence on extended semen [10]. The storage of human sperm cells in media with increasing $\mathrm{pH}$ has resulted in an increase in intracellular $\mathrm{pH}[3]$. Thus, it appears that the $\mathrm{pH}$ differences observed in the present study were responsible for changes in the motility and kinematic parameters. Most extenders, such as the BTS used in this trial, cause a considerable reduction of intracellular $\mathrm{pH}$ below 6.0, which enables the cells to survive storage for some days [6]. However, under alkaline conditions, the mitochondrial activity of the sperm is increased and their lifespan is diminished. Therefore, it has been proposed that saving unnecessary expenditure of energy may have a major role in prolonged conservation of motility [14]. It has been demonstrated an inverse relation between the $\mathrm{pH}$ of the medium and the sperm motility, indicating that the external $\mathrm{pH}$ has a direct influence on sperm metabolism [7]. Indeed, lower velocity parameters and lower percentages of motile and progressively motile sperm have been reported after $60 \mathrm{~h}$ for semen doses stored with increasing air volume and increasing $\mathrm{pH}$ [15].

The detrimental effect of air on sperm quality could also be related to the high susceptibility of porcine sperm to oxidative stress [1]. Boar spermatozoa show a high content of polyunsaturated fatty acids on their plasma membrane, which work as potential substrate for reactive oxygen species formation [2]. In the presence of air, sperm cells use the oxygen available to create ATP (adenosine triphosphate) through aerobic respiration [9]. Since free radicals are formed as natural byproducts of the normal metabolism of oxygen, the air within semen doses might increase the production of these compounds, leading to losses in sperm function.

Although the acrosome integrity was not affected by the amount of air, the acrosome became more susceptible to damage over the storage time. This decrease in acrosome integrity might be due to the ageing process of the spermatozoa, a natural phenomenon that cannot be prevented [6]. It was already expected that, during storage time, sperm undergo structural and functional changes, culminating in possible losses in their capacity of fertilization [16].

The thermoresistance test was performed in order to estimate sperm performance in the female genital tract after artificial insemination [12]. The aim was to reveal sperm latent damage, which is not usually detectable by routine evaluation [4]. In this study, after both $30 \mathrm{~min}$ and $120 \mathrm{~min}$ of TRT, the percentage of total motility, progressive motility and rapid motility were higher in semen doses that had no air entrapped within the tubes and, as a consequence, had a lower $\mathrm{pH}$. In a recent study [13], semen samples under an alkaline environment ( $\mathrm{pH}$ 7.3-7.5) had loss of motility and changes in sperm kinematics parameters after a prolonged thermoresistance test $\left(300 \mathrm{~min}\right.$ at $\left.38^{\circ} \mathrm{C}\right)$, highlighting the negative effect of the $\mathrm{pH}$-rise on the longevity of sperm cells.

\section{CONCLUSION}

The presence of air negatively affects the quality of extended semen during storage, and the amount of entrapped air within the tubes is relevant. Although the effect of the air presence on sperm motility was only evident at $72 \mathrm{~h}$ and $120 \mathrm{~h}$ of storage, the $\mathrm{pH}$ was already affected from $24 \mathrm{~h}$ onwards. Therefore, minimizing the contact of extended semen with air is advisable in order to preserve the quality of semen doses. Nevertheless, further studies should be performed to investigate other seminal parameters that may be influenced by the maintenance of air within doses.

\section{MANUFACTURERS}

${ }^{1}$ Minitüb GmbH. Tiefenbach, Germany.

${ }^{2}$ Shimadzu do Brasil Comércio. Barueri, SP, Brazil.

${ }^{3}$ Leja Products B.V. Nieuw-Vennep, The Netherlands.

${ }^{4}$ Carl Zeiss Group. Oberkochen, Germany.

${ }^{5} \mathrm{~B}$. Braun Medical Inc. Allentown, PA, USA.

${ }^{6}$ Quimis Aparelhos Científicos LTDA. Diadema, SP, Brazil.

Ethical approval. Process $\mathrm{n}^{\circ} 28591$ approved by the Ethical Committee of Animal Utilization - CEUA - of UFRGS.

Declaration of interest. The authors report no conflicts of interest. The authors alone are responsible for the content and writing of the paper.

\section{REFERENCES}

1 Ausejo R., Dahmani Y., Mendoza N. \& Yeregui J. 2015. Effect of an air chamber in stored boar seminal doses. Reproduction in Domestic Animals. 50(Suppl. 2): 124.

2 Cerolini S., Maldjian A., Surai P. \& Noble R. 2000. Viability, susceptibility to peroxidation and fatty acid composition of boar semen during liquid storage. Animal Reproduction Science. 58: 99-111. 
3 Cross N.L. 2007. Effect of $\mathrm{pH}$ on the development of acrosomal responsiveness of human sperm. Andrologia. 39: 55-59.

4 Fiser P.S., Hansen C., Underhill L. \& Marcus G.J. 1991. New thermal stress test to assess the viability of cryopreserved boar sperm. Cryobiology. 28: 454-459.

5 Hancock J.L. \& Hovell G.J.R. 1959. The collection of boar semen. The Veterinary Record. 71: 664-665.

6 Johnson L.A., Weitze K.F., Fiser P. \& Maxwell W.M.C. 2000. Storage of boar semen. Animal Reproduction Science. 62: 143-172.

7 Jones J.M. \& Bavister B.D. 2000. Acidification of intracellular pH in bovine spermatozoa suppresses motility and extends viable life. Journal of Andrology. 21: 616-624.

8 Pinart E., Veste M., Prieto-Martínez N., Reixach J. \& Bonet S. 2015. Sperm quality and fertility of boar seminal doses after 2 days of storage: Does the type of extender really matter? Theriogenology. 83: 1428-1437.

9 Pipan M.Z., Mrkun J., Kosec M., Svete A.N. \& Zrimšek P. 2014. Superoxide dismutase: A predicting factor for boar semen characteristics for short-term preservation. BioMed Research International. Article 105280, 7p. doi:10.1155/2014/105280.

10 Purdy P.H., Tharp N., Stewart T., Spiller S.F. \& Blackburn H.D. 2010. Implications of the pH and temperature of diluted, cooled boar semen on fresh and frozen-thawed sperm motility characteristics. Theriogenology. 74: 1304-1310.

11 Riesenbeck A., Schulze M., Rüdiger K., Henning H. \& Waberski D. 2015. Quality control of boar sperm processing: Implications from European AI centres and two spermatology reference laboratories. Reproduction in Domestic Animals. 50 (Suppl 2): 1-4.

12 Schulze M., Rüdiger K., Jung M. \& Grossfeld R. 2015. Use of refractometry as a new management tool in AI boar centers for quality assurance of extender preparations. Animal Reproduction Science. 152: 77-82.

13 Schulze M., Rüdiger K. \& Waberski D. 2015. Rotation of boar semen doses during storage affects sperm quality. Reproduction in Domestic Animals. 50: 684-687

14 Vishwanath R. \& Shannon P. 1997. Do sperm cells age? A review of the physiological changes in sperm during storage at ambient temperature. Reproduction, Fertility and Development. 9: 321-331.

15 Vyt D., Maes S.U., Sys T., Rijsselaere A. \& Van Soom A. 2007. Air contact influences the pH of extended porcine semen. Reproduction in Domestic Animals. 42(2): 218-220.

16 Waberski D., Meding S., Dirksaen G., Weitze K.F., Lewiding C. \& Hahn R. 1994. Fertility of long term-stored boar semen: influence of extender (Androhep and Kiev), storage time and plasma droplets in the semen. Animal Reproduction Science. 36: 145-151. 